\title{
Knowledge and Attitude of Cancer Patients Towards COVID-19 Pandemic
}

\section{Sobia Yaqub, ${ }^{1}$ Zahid Jamil, ${ }^{2}$ Numrah Bilal Butt, ${ }^{3}$ Amjad Zafar, ${ }^{4}$ Faiza Rehman Lodhi, ${ }^{5}$ Muhammad Abbas Khokhar ${ }^{6}$}

\begin{abstract}
Objectives: This study is done to determine knowledge and attitude of cancer patients towards COVID-19 pandemic.

Methods: The study was conducted at Oncology Department, Mayo Hospital Lahore during August-October 2020. A questionnaire was used to determine knowledge and attitude of cancer patients towards COVID-19 pandemic. Data was analyzed using Spss version.23. Descriptive variables like gender, marital status, residence and disease characteristics were reported as means and frequencies. Intergroup analysis was done using Chi square test with $\mathrm{p}<0.05$ taken as significant.

Results: Of 269 enrolled patients, majority had advanced/metastatic disease $(82.4 \%)$ and were being treated on outdoor basis (71.6\%). Almost all (99.6\%) were aware of COVID, electronic/print media being commonest source of information $(62.7 \%)$. Though having different views, $81.5 \%$ considered it a natural calamity. During first wave,22.4\% had delayed their investigations while $34.7 \%$ faced treatment interruptions with average duration of delay being $55 \pm 27$ days. Traveling difficulties due to lock down was common reason of delay (54.8\%). During this period $62.4 \%$ either noted worsening of symptoms or new symptoms. Despite all chaos, $89.9 \%$ selected for treatment continuation if provided with a chance and appropriate facilities. Correlation of delay in therapy with high level of education $(\mathrm{p}=0.013)$ and perception about COVID-19 a natural calamity $(\mathrm{p}=0.041)$ was found to be statistically significant.

Conclusion: Patients' perspective is important and should be taken into account in special circumstances like COVID. It will help in future in making efficient management planning of disease during unusual situations.

Key Words: COVID-19, cancer patients, Knowledge

How to cite: Yaqub S., Jamil Z., Butt. B.N., Zafar A., Lodhi R.F., Khokhar A.M. Knowledge and attitude of cancer patients towards COVID-19 pandemic. Esculapio 2021;17(01):26-29

DOI: https://doi.org/10.51273/esc21.251715
\end{abstract}

\section{Introduction}

Orona virus infection, named COVID-19 by WHO, is caused by SARS-COV2, which is primarily a respiratory virus. It emerged as global health problem by end of 2019, starting in China when people presented with pneumonia like illness and were diagnosed as having Corona virus infection. ${ }^{1}$ WHO declared. ${ }^{2}$ It as pandemic due to its rapid spread across the globe. ${ }^{(2)}$ it resembles other pneumonia in its

\begin{tabular}{|c|c|}
\hline 1. Sobia Yaqub & 2. Zahid Jamil \\
\hline 3. Numrah Bilal Butt & 4. Amjad Zafar \\
\hline 5. Faiza Rehman Lodhi & 6. Muhammad Abbas Khokhar \\
\hline
\end{tabular}

Correspondence:

Dr. Sobia Yaqub, Department of Oncology, King Edward Medical University. Email: sobia_yaqub@yahoo.com

$\begin{array}{ll}\text { Submission Date: } & 03-02-2021 \\ \text { 1st Revision Date: } & 12-02-2021 \\ \text { Acceptance Date: } & 25-02-2021\end{array}$

symptomatology but have a rapid rate of transmission. ${ }^{3}$ Most common clinical features include dry cough, fever, lethargy, sore throat, runny nose, alteration in taste and smell sensation. Severity of disease varies widely from asymptomatic to seriously sick requiring invasive ventilation ${ }^{4,5}$ Pakistan became affected by this pandemic by end of February with rapid surge of cases seen in March. To handle such an influx of COVID-19 cases, government imposed smart lock in the country. ${ }^{6}$ This situation affected routine social life and exerted detrimental financial issues $^{7}$ With emergence of COVID-19, increased cost, decreased monthly income, travelling difficulties and fear of getting Corona virus illness led to marked reduction in acquisition of health care facilities. ${ }^{8}$ As per available data, cancer patients have higher risk of catching COVID-19 infection attributing greatly to frequent hospital visits apart from other patient and disease factors. ${ }^{9}$ 


\section{Methods}

Patients of various malignancies presenting to Department of Medical Oncology and Radiotherapy, KEMU/ Mayo hospital Lahore, were enrolled in study after taking informed consent. Data was collected via questionnaire. Various demographic factors like age, gender, diagnosis, stage was inquired. Questions were asked to know about their level of knowledge about COVID-19, and how they responded to this pandemic in terms of preventive measures, delays in cancer care, if any, and its possible consequences on life of cancer patients.

Collected data was entered and analyzed using statistical package for social sciences (SPSS) version 23. An initial frequency counts and percentages were obtained for all the data. Descriptive statistics were reported as mean, frequency and percentage. Intergroup comparisons were performed using ChiSquare test. All $\mathrm{p}$ values $<0.05$ were reported as statistically significant.

\section{Results}

The study subjects $(\mathrm{n}=269)$ comprised $128(47.6 \%)$ males and $141(52.4 \%)$ females with age range between 11-66years (mean 44 14.40 ). Almost all the patients (99.6\%) were aware of COVID-19 pandemic.184 $(68.7 \%)$ were found to be aware of symptoms correctly and $218(81.3 \%)$ perceived it as a different illness from common flu. A total of 216(80.6\%) patients were found to be following precautionary measures as advised by authorities. When asked about risk of acquiring COVID illness by cancer patients, 196 (73.1\%) responded an increased risk to cancer patients while $72(26.9 \%)$ said that cancer patients have risk equivalent to general population. During first wave, $22.4 \%$ had delayed their investigations while treatment interruptions were seen in $34.7 \%$ patients with average duration of delay being $55 \pm 27$ days and traveling difficulties due to lock down commonest reason of delay (54.8\%). During this period $62.4 \%$ either noted worsening of symptoms or new symptoms. Despite this great threat, and increasing number of cases, only $27(10.1 \%)$ patients opted for discontinuation of their cancer therapy while $241(89.9 \%)$ decided to continue the therapy when given a choice. Correlation of delay in therapy with high level of education $(\mathrm{p}=0.013)$ and perception about COVID-19 a natural calamity ( $\mathrm{p}=$ 0.041 ) was found to be statistically significant.
Table 1: Demographic Data of Patients Included in the Study

\begin{tabular}{|c|c|c|}
\hline Demographics & Count & $\%$ age \\
\hline Total Number of Patient & $\mathrm{n}=269$ & 100 \\
\hline \multicolumn{3}{|l|}{ Gender } \\
\hline Male & 128 & 47.58 \\
\hline Female & 141 & 52.42 \\
\hline \multicolumn{3}{|l|}{ Marital Status } \\
\hline Married & 229 & 85.13 \\
\hline Unmarried/Single & 40 & 14.87 \\
\hline \multicolumn{3}{|l|}{ Residence } \\
\hline Rural & 127 & 47.21 \\
\hline Urban & 142 & 52.79 \\
\hline \multicolumn{3}{|l|}{ Disease Characteristics } \\
\hline Diagnosis & Count & $\%$ age \\
\hline Unknown & 17 & 6.32 \\
\hline Hematological Malignancies & 75 & 27.88 \\
\hline Non-Hematological Malignancies & 178 & 66.17 \\
\hline Stage & Count & $\%$ age \\
\hline Early Stage & 16 & 5.95 \\
\hline Advanced or Metastatic & 253 & 94.05 \\
\hline \multicolumn{3}{|l|}{ Patient Characteristics: } \\
\hline Qualification & Count & $\%$ age \\
\hline Unknown & 32 & 11.89 \\
\hline Illiterate & 96 & 35.68 \\
\hline$\leqslant 10$ grade & 117 & 43.49 \\
\hline$>10^{\text {th }}$ grade & 24 & 8.91 \\
\hline Mode of Transportation & Count & $\%$ age \\
\hline Private Transport & 16 & 5.95 \\
\hline Public Transport & 253 & 94.05 \\
\hline Diagnosis & Count & $\%$ age \\
\hline Unknown & 17 & 6.32 \\
\hline Hematological Malignancies & 75 & 27.88 \\
\hline Non-Hematological Malignancies & 178 & 66.17 \\
\hline Stage of Disease & Count & $\%$ age \\
\hline Early Stage & 17 & 6.32 \\
\hline Advanced or Metastatic & 252 & 93.68 \\
\hline Mode of Treatment & Count & $\%$ age \\
\hline OPD Basis & 193 & 71.75 \\
\hline As Indoor Patient & 76 & 28.25 \\
\hline Average Number of rooms in house & \multicolumn{2}{|c|}{$3.25 \pm 1.36$} \\
\hline Average Number of family members & \multicolumn{2}{|c|}{$7.29 \pm 2.33$} \\
\hline
\end{tabular}

\section{Discussion}

SARS -COV2 infection has affected people of $>150$ countries of the world with patients presenting primarily with respiratory symptoms though varied presentation due to involvement of other body systems is not uncommon. Virus mediated tissue damage, endothelial injury, impaired immune function are common pathogenic mechanisms explaining vast spectrum of its clinical manifestations. ${ }^{10,11}$ 
Table 2: Knowledge of Cancer Patients Towards COVID-19

\begin{tabular}{lcc}
\hline & Number & \%age \\
\hline Source of Information: & & \\
Electronic/print media & 168 & 62.7 \\
Social media & 29 & 10.8 \\
Relatives/friends & 66 & 24.6 \\
Health care worker & 4 & 1.5 \\
View about COVID -19 & & \\
Natural calamity & 212 & 81.5 \\
Plot by government & 12 & 4.6 \\
Man-made virus & 17 & 6.5 \\
It has no existence & 16 & 6.2 \\
Is it a threat to life? & & \\
Major threat & 123 & 45.9 \\
Mild threat & 86 & 32.1 \\
No threat at all & 20 & 7.5 \\
Mode of transmission & & \\
Via droplets & 153 & 57.1 \\
Air borne transmission & 21 & 7.8 \\
Person to person & 68 & 25.4 \\
Via contaminated food & 12 & 4.5 \\
COVID case in friends/relatives & & \\
Yes & 69 & 25.7 \\
No & 200 & 74.3 \\
Death due to COVID in friends/family & & \\
Yes & 16 & 64.05 \\
No & & \\
\hline & & \\
\hline
\end{tabular}

\section{Impact of COVID-19 on Cancer Management}

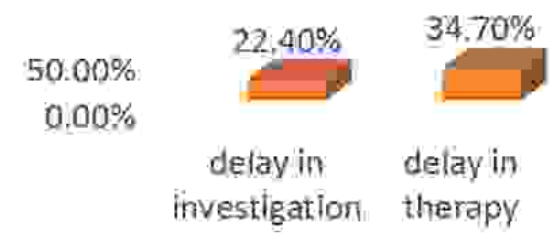

Fig. 1: Impact of COVID-19 on Cancer Management

Reasons for Delay in therapy

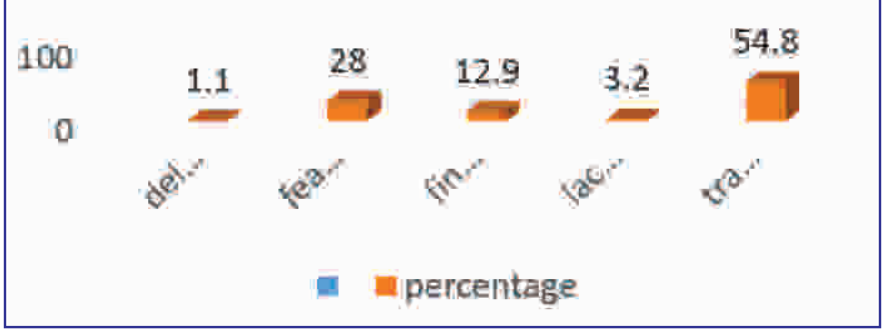

Fig. 2: Reasons for Delay in Therapy

Data has shown increased morbidity and mortality in cancer patients as compared with general population.
Old age at presen-tation, weakened immune system, presence of multiple co-morbidities, need of frequent hospital visits are important reasons of increased vulnerability of cancer patients towards COVID-19 illness. ${ }^{9}$ In a study, all cause 30 days mortality was found to be significantly higher in cancer patients. ${ }^{12}$ Diagnosis of cancer in general is considered as death sentence to affected. It is common observation that people when diagnosed with chronic lethal disease like cancer, let no stone unturned to get rid of it which often proves to be a futile effort. To achieve an effective cure/ symptomatic relief of symptoms is a physical and psychological trauma to patients and his/her caregivers. It poses social, psychological, financial burden on their lives but they continue their fight for survival.

COVID-19, with its strikingly high spread across the world, compelled governing authorities to impose lock down to control rate of transmission. It was implemented in almost all countries including Pakistan. This lock down apart from achieving its primary goal, exerted great difficulties in life of people especially developing countries like Pakistan where people suffered greatly not only from financial and social issues but also mental and physical health related issues. Health issues were partly from fear of getting corona infection and largely due to economic burden, travelling difficulties and non-availability of effective health care services.

In this study, we focused on perspective of cancer patients towards this pandemic. The study showed that advancement of telecommunication has led every one aware of the disease though majority of the respondents were illiterate and belonging to poor socio-economic status. Despite facing so many difficulties, majority having advanced incurable disease and different believes towards nature of COVID illness, treatment delays were seen in only $34.7 \%$ of patients which was largely due to travelling difficulties. It shows that although they have higher risk of potentially life-threatening illness, people opted for cancer treatment as they considered it more important likely because it is an issue which has greater impact on their health and lives. Important is to note that correlation of delay in therapy with level of education and their views about pandemic was found to be significant. It emphasizes that particular attention should be given to education of our people so they better understand exact nature of various illnesses 
and their impacts which in turn lead to improvement in health of our people.

\section{Conclusion}

There is a strong need that we should focus on patients' perspective regarding their chronic debilitating illnesses like cancer in special circumstances like COVID-19 pandemic. This will help us in making effective strategies towards management of diseases like cancer without losing control during unexpected situations like pandemic.

\section{References}

1. Rothan HA, Byrareddy SN. The epidemiology and pathogenesis of coronavirus disease (COVID-19) outbreak. Journal of autoimmunity. 2020 Feb 26: 102433.

2. Spinelli A, Pellino G. COVID-19 pandemic: perspectives on an unfolding crisis. The British journal of surgery. 2020 Mar 19.

3. Zhao D, Yao F, Wang L, Zheng L, Gao Y, Ye J, Guo F, Zhao H, Gao R. A comparative study on the clinical features of COVID-19 pneumonia to other pneumonias. Clinical Infectious Diseases. 2020 Mar 12.

4. Lovato A, de Filippis C. Clinical presentation of COVID-19: a systematic review focusing on upper airway symptoms. Ear, Nose \& Throat Journal. 2020 Apr 13:0145561320920762.

5. Macera M, De Angelis G, Sagnelli C, Coppola N, COVID V. Clinical Presentation of COVID-19: Case Series and Review of the Literature. International Journal of Environmental Research and Public Health. 2020 Jan;17(14):5062.

6. Nafees M, Khan F. Pakistan's Response to COVID19 Pandemic and Efficacy of Quarantine and Partial Lockdown: A Review. Electron J Gen Med. 2020; 17 (6): em240.

7. Ali A, Ahmed M, Hassan N. Socioeconomic impact of COVID-19 pandemic: Evidence from rural mountain community in Pakistan. Journal of Public Affairs. 2020 Aug 24:e2355.

8. Ahmed SA, Ajisola M, Azeem K, Bakibinga P, Chen YF, Choudhury NN, Fayehun O, Griffiths F, Harris B, Kibe P, Lilford RJ. Impact of the societal response to COVID-19 on access to healthcare for non-COVID19 health issues in slum communities of Bangladesh, Kenya, Nigeria and Pakistan: results of pre-COVID and COVID-19 lockdown stakeholder engagements. BMJ global health. 2020 Aug 1;5(8):e003042.

9. Kuderer NM, Choueiri TK, Shah DP, Shyr Y, Rubinstein SM, Rivera DR, Shete S, Hsu CY, Desai A, de Lima Lopes Jr G, Grivas P. Clinical impact of COVID19 on patients with cancer (CCC19): a cohort study. The Lancet. 2020 May 28.

10. Hanna TP, Evans GA, Booth CM. Cancer, COVID19 and the precautionary principle: prioritizing treatment during a global pandemic. Nature Reviews Clinical Oncology. 2020 May;17(5):268-70.

11. Gupta A, Madhavan MV, Sehgal K, Nair N, Mahajan S, Sehrawat TS, Bikdeli B, Ahluwalia N, Ausiello JC, Wan EY, Freedberg DE. Extrapulmonary manifestations of COVID-19. Nature medicine. $2020 \mathrm{Jul}$; 26(7): 1017-32.

12. Warner JL, Rubinstein S, Grivas P, Choueiri TK, Kuderer NM, Shah D, Rivera DR, Gupta S, Bilen MA, Halfdanarson TR, Doroshow DB. Clinical impact of COVID-19 on patients with cancer: Data from the COVID-19 and Cancer Consortium (CCC19).

\section{Authors Contribution}

SY,MAK: Conceptionlization of Project

ZJ,NBB: Data Collection

SY: Literature Search

SY,AZ: Statistical Analysis

FRL: Drafting, Revision

SY,AZ,MAK: Writing of Manuscript 